\title{
ADOECIMENTO DOCENTE: UMA BREVE ANÁLISE DA SAÚDEDE PROFESSORES DO MUNICÍPIO DE MEDEIROS NETO/BA
}

\author{
Jafé da Silva Cardoso(*) \\ Claudio Pinto Nunes ${ }^{(* *)}$ \\ Juliana Silva Moura ${ }^{(* * *)}$
}

\section{INTRODUÇÃO}

Numa sociedade em relativo aceleramento da dinâmica da vida contemporânea em diversos segmentos, também se observa uma curva ascendente nos números referentes à violência, à carga de trabalho e à intolerância, fatores que incidem na situação dos profissionais em educação, por estes estarem cotidianamente em contato com tal realidade e à mercê das doenças e síndromes suscitadas por esse ambiente nocivo de trabalho. Diante disso, observa-se a importância de se discutir este tema a fim de elaborar um entendimento acerca da situação da educação, de modo geral, e dos educadores, de modo mais específico, que, em muitos casos, estão sendo obrigados a deixarem de lado os ofícios da profissão por conta da exaustão e do consequente adoecimento.

$\mathrm{Na}$ correria da sociedade atual, é cada vez mais frequente o adoecimento e o afastamento de inúmeros profissionais de suas funções devido a complicações de saúde. $\mathrm{O}$ trabalho, que antes era visto como realização e/ou forma de sobrevivência, passa a ser um fardo, acarretando a queda de seu rendimento e de seu comprometimento como profissional, ou até mesmo o afastamento desses indivíduos do convívio social, dentre outras problemáticas.

Esta realidade toma contornos mais negativos dentro de profissões que estão cotidianamente em contato com outros seres humanos, como é o caso dos profissionais da área da saúde e educação. Identificar os motivos dessa problemática constitui um dos grandes desafios da sociedade atual, uma vez que inúmeras razões são apontadas como desencadeadoras de tal agravo.

\footnotetext{
(*) Mestrando em Educação pela Universidade Estadual do Sudoeste da Bahia (UESB). Coordenador pedagógico da Rede Municipal de Medeiros Neto/BA. Grupo de Estudos e Pesquisas Movimentos sociais, Diversidade e Educação do Campo (GEPEMDEC/CNPq). Orcid: 〈https://orcid.org/0000-0003-1391-8307>.

${ }^{(* *)}$ Doutor em Educação pela Universidade Federal do Rio Grande do Norte (UFRN). Pós-doutor em Educação pela Universidade Federal de Minas Gerais (UFMG). Professor titular da Universidade Estadual do Sudoeste da Bahia (UESB) e do Programa de Pós-graduação em Educação. Líder do Grupo de Pesquisa Didática, Formação e Trabalho Docente (Difort/CNPq). Orcid: <https://orcid.org/0000-0001-5924-9124>.

${ }^{(* * *)}$ Mestranda em Educação pela Universidade Estadual do Sudoeste da Bahia (UESB). Psicóloga da Rede Municipal de Saúde de Itapetinga/BA. Membro do Grupo de Pesquisa Didática, Formação e Trabalho Docente (Difort/CNPq). Orcid: <https://orcid.org/0000-0001-7488-031X>.
} 
Voltando-nos para a área da educação, que é o foco principal deste trabalho, as razões apontadas centram-se mais especificamente nos seguintes fatores: precarização das condições de trabalho; baixa remuneração; sobrecarga de trabalho; falta de reconhecimento e baixa valorização profissional; aumento da violência no cotidiano escolar (principalmente de alunos contra professores) e a insatisfação dos profissionais com as demandas cotidianas da profissão.

É importante frisar que os fatores mencionados reapresentam apenas uma pequena parcela diante de um contexto ainda desconhecido, sendo certa apenas a informação de que o adoecimento dos profissionais da educação é cada vez mais frequente e o contingente de profissionais que abandonam a profissão por esse motivo cresce consideravelmente a cada ano.

Esta pesquisa justifica-se porque, ainda que essa realidade esteja presente em quase todos os municípios brasileiros, a vivência e observação informal no ambiente de trabalho de professores trouxe a percepção de que o número de educadores afastados por motivo de saúde é consideravelmente elevado, em se tratando de um município de dimensão geográfica tão pequena, como é o caso do município de Medeiros Neto, BA.

Mediante a situação observada, e pautando-se na compreensão de que as funções atuais do professor, que diferem muito das funções que este profissional desempenhava no passado, este passando a acumular também a função de gestor, de organizador, bem como de elo entre comunidade e escola são, possivelmente, fatores que incidem na saúde destes profissionais, surgiu a iniciativa de desenvolver este projeto.

Este artigo buscou analisar a realidade docente para então compreender os motivos de tal adoecimento, destacando também a repercussão que o afastamento do professor traz para o seu desempenho profissional. As reflexões aqui propostas não dizem respeito à solução dos problemas e/ou a sua erradicação, mas firmam-se como um alerta para toda classe, suscitando a valorização e o entendimento da prevenção como arma mais importante para se evitar o aparecimento de novos casos.

\section{A PRECARIZAÇÃo PROFISSIONAL E SUA RELAÇÃO COM O PROCESSO DE ADOECIMENTO DOCENTE}

A situação atual da saúde dos profissionais em educação é reflexo direto das mudanças ocorridas nas funções exercidas pelos mesmos ao longo do processo de desenvolvimento da educação brasileira. A função da escola, que antes era a formação do indivíduo e seu desenvolvimento, passou a ser outra bem distinta, e passou a ter também papel de formadora de 
trabalhadores para atender à demanda do mercado. E se a função da escola tomou uma nova direção, a dos docentes também seguiu essa nova vertente, assumindo a responsabilidade de formar trabalhadores e não apenas mediar conhecimento. Ao assumir essa nova função, imediatista e capitalista, “[...] o professor se vê submetido às mesmas condições dos trabalhadores fabris, pois a escola adquire a nova função de formar trabalhadores. $\mathrm{O}$ aluno passa a ser visto como produto e a escola como uma instituição produtora da força de trabalho" (FRANCELINO, 2003, p. 136).

Nota-se, de acordo com Esteves (1999), que, com as transformações ocorridas, o professor, um dos principais atores desse cenário, acompanha perplexo esse novo contexto e as novas exigências e responsabilidades, desafiado a assumir um papel diferente do até então exercido e, ao assumir essas novas funções, ele acabou por ser vítima da sobrecarga de trabalho, do estresse, da falta de valorização profissional e financeira, surgindo daí as inúmeras doenças e síndromes que acometem os profissionais docentes no cotidiano do trabalho.

Dialogando com esta problemática, Reis et al. (2006) asseveram que ensinar é uma atividade, em geral, altamente estressante, com repercussões evidentes na saúde física e mental e no desempenho profissional dos professores. Isso se evidencia pelo grau de envolvimento e comprometimento do docente diante do ato de ensinar que é, por excelência, um ato de troca, de contato. Estes autores afirmam ainda que, quando os objetivos não são alcançados, o resultado torna-se desastroso para o professor que, engajado com sua profissão, se frustra diante da não obtenção de êxito, da falta de reconhecimento e valorização, e essa frustração, por sua vez, pode acarretar sérias consequências à saúde do profissional.

Ao se analisar o resultado das diversas pesquisas lançadas sobre a temática, observa-se que o sexo feminino é o mais atingindo, talvez porque as mulheres somem um número mais expressivo na carreira docente. Contudo, não é somente o fato de ser em maior número na profissão o que determina que as mulheres sejam as mais atingidas, mas soma-se a isso a função desempenhada pela mulher no seio familiar, que é a de mãe, esposa, doméstica etc. Esses e outros fatores contribuem para que as docentes sejam as mais afetadas pelas doenças que assolam os profissionais em educação, podendo-se afirmar que

As tarefas que integram o trabalho doméstico são muito diversificadas quanto a sua complexidade, indo desde os serviços domésticos até o cuidado e a educação dos filhos. Soma-se a isso que o trabalho docente exige uma jornada dupla de trabalho, [...] (ROCHA; SARRIERA, 2006, p. 191).

Diante desta realidade, o professor encontra-se quase sem ou com sem nenhum suporte, estando quase sempre à mercê de todas essas mazelas, e o resultado são os inúmeros casos de 
afastamento desses profissionais, que são vítimas da exaustão, de síndromes diversas, como a de burnout, entre outras. Com base em todos esses fatos e nas concepções de Tavares, entendemos que ser professor é:

[...] uma das profissões mais estressantes na atualidade. Geralmente as jornadas de trabalho dos professores são longas, com raras pausas de descanso e/ou refeições breves e em lugares desconfortáveis. O ritmo intenso e variável, com início muito cedo pela manhã, podendo ser estendido até à noite em função de dupla ou tripla jornada de trabalho. No corre-corre os horários são desrespeitados, perdem-se horas de sono alimenta-se mal, e não há tempo para o lazer. São exigidos níveis de atenção e concentração para a realização das tarefas. Quando o trabalho é desprovido de significação, não é reconhecido ou é uma fonte de ameaças à integridade física e/ou psíquica acaba por determinar sofrimento ao professor. (TAVARES, 2007, p. 19).

Essas asserções nos mostram que o trabalho para esses indivíduos acaba por se tornar algo frustrante, posto que o sofrimento se mostra mais pertinente do que a satisfação, e o isolamento torna-se o único refúgio e saída. E, como coloca Dejours (1992), o trabalho nem sempre possibilita realização profissional, e pode, ao contrário, causar problemas, desde insatisfação até exaustão. Ainda seguindo este raciocínio, Maslach e Leiter (1997, p. 129) acrescentam que:

[...] os indivíduos que estão neste processo de desgaste estão sujeitos a largar o emprego, tanto psicológica quanto fisicamente. Eles investem menos tempo e energia no trabalho, fazendo somente o que é absolutamente necessário e faltam com mais frequência. Além de trabalharem menos, não trabalham tão bem. Trabalho de alta qualidade requer tempo e esforço, compromisso e criatividade, mas o individuo desgastado já não está disposto a oferecer isso espontaneamente. A queda na qualidade e na quantidade de trabalho produzido é o resultado profissional do desgaste.

As concepções destes autores demonstram o quanto os fatores aqui apresentados, considerados pela maioria como supérfluos, podem acarretar a completa destruição da vida pessoal e profissional desses indivíduos. O aporte teórico ora apresentado pode ser considerado irrisório diante da complexidade da proposta aqui apresentada. Contudo, como se trata de um estudo preliminar, o mesmo consegue suprir as necessidades deste estudo, que ainda é incipiente. Entretanto, ao se objetivar uma análise mais profunda e um estudo mais detalhado sobre o tema, compete uma busca mais detalhada, embora haja carência de trabalhos científicos com abordagem mais aprofundada sobre o assunto. 


\section{METODOLOGIA}

Os objetivos norteadores desta pesquisa estão calcados na pressuposição de que as doenças que afligem os profissionais em educação estão diretamente ligadas aos problemas enfrentados pelos mesmos no cotidiano de sua profissão, com ênfase em alguns aspectos, tais como sobrecarga de trabalho, insatisfação profissional, acúmulo de funções, crescente violência no cotidiano escolar, dentre outros.

Esta pesquisa foi realizada tendo como base os dados do Departamento de Recursos Humanos da Prefeitura Municipal de Medeiros Neto, Bahia, referentes ao número de docentes afastados de suas funções por motivos de saúde. Foi solicitado, através de ofício encaminhado à Secretaria Municipal de Educação e Cultura do referido município, a autorização para a liberação do quantitativo dos profissionais docentes que estiveram/estavam afastados por motivo de doenças. O cruzamento de dados desses dois departamentos foi necessário para dar maior credibilidade ao resultado encontrado.

Em linhas gerais, ressalva-se que a metodologia empregada nesta pesquisa pautou-se no viés qualiquantitativo, objetivando levantar as principais causas do afastamento dos profissionais em educação.

Além das bases de dados citadas, foi realizada outra coleta, na qual se utilizou um questionário, cujas perguntas foram direcionadas a professores da rede municipal de ensino, tanto do quadro efetivo quanto dos contratados. Esta opção de se realizar a entrevista envolvendo as duas modalidades de vínculo dos docentes foi adotada porque, de acordo com alguns dados anteriormente encontrados, em ambas as situações contratuais ocorreram afastamentos. $\mathrm{O}$ roteiro da entrevista foi previamente elaborado com 10 questões, referentes aos seguintes aspectos: a) satisfação com a profissão; b) preocupação com a saúde; c) carga de trabalho; d) relações efetivas; e) a doença e o afastamento.

As entrevistas foram realizadas com 20 profissionais cujos nomes constavam nos dados coletados como sendo indivíduos que já sofreram algum tipo de problema de saúde e que foram afastados devido a ele. Todos os nomes escolhidos foram do sexo feminino. Esta escolha se deu porque não foram encontradas referências a profissionais docentes do sexo masculino que tenham solicitado afastamento de suas funções pelos motivos suscitados na presente pesquisa. Todos os nomes pesquisados se referem a professoras que lecionam na sede do município pesquisado. 


\section{RESULTADOS DA PESQUISA}

A entrevista se pautou nas condições de trabalho e saúde dos professores. Assim, ao serem questionadas sobre o grau de satisfação na profissão, houve um empate em relação a este aspecto, sendo que $43 \%$ relataram estarem satisfeitas com a docência e o mesmo percentual declarou estar pouco satisfeitas com a profissão. Os demais $14 \%$ afirmaram estar muito satisfeitas, conforme se verifica no gráfico 1 .

\section{Gráfico 1. Grau de satisfação diante da profissão}

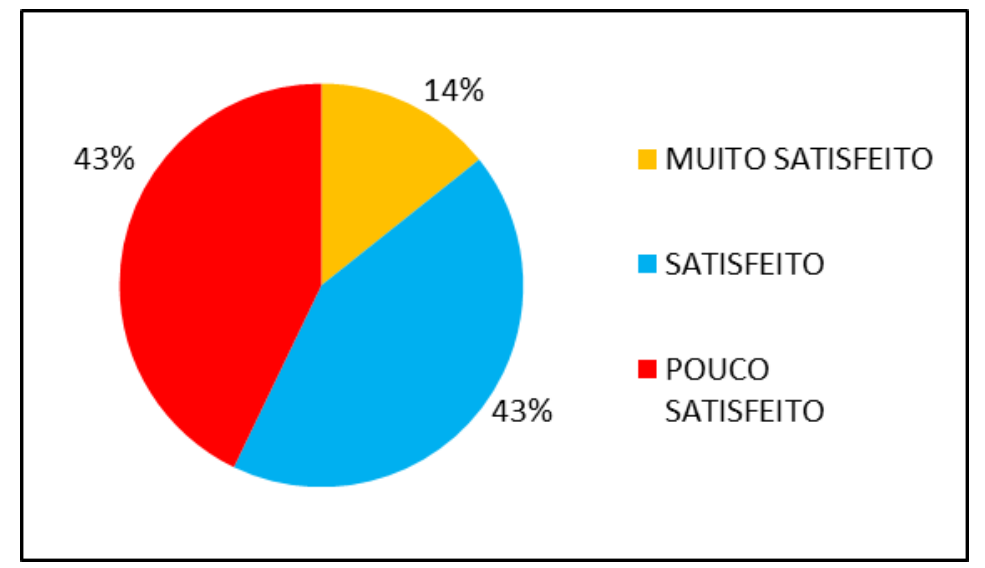

O quantitativo apresentado no gráfico 1 expressa a incerteza docente frente a seu grau de satisfação. Esse resultado aponta que as novas exigências educacionais, as novas funções assumidas pelo docente, oriundas, em grande parte, do esfacelamento familiar da maioria dos discentes, tem imputado ao docente sobrecarga que o desmotiva, aliena e, em partes, o leva ao estresse, à exaustão e, enfim, ao adoecimento físico e mental. Segundo Heller (1985, p. 38), [...] "existe alienação quando ocorre um abismo [...] entre a produção humano-genérica e a participação consciente do indivíduo nessa produção". São adequadas aqui também às concepções de Marx sobre alienação, que traduzem consideravelmente os sentimentos apontados pelos docentes ao longo dos relatos, que expressam a dubiedade entre estar ou não satisfeito com o trabalho desempenhado, fato que, segundo Marx (1974, p. 162), ocorre devido ao trabalhador sentir que o trabalho é exterior a si:

[...] quer dizer, não pertence à sua natureza; portanto, ele não se afirma no trabalho, mas nega-se a si mesmo, não se sente bem, mas infeliz, não desenvolve livremente as energias físicas e mentais, mas esgota-se fisicamente e arruína o espírito. Por conseguinte, o trabalhador só se sente em si fora do trabalho, enquanto no trabalho se sente fora de si. Assim, o seu trabalho não é voluntário, mas imposto, é trabalho forçado. Não constitui a satisfação de uma necessidade, mas apenas um meio de satisfazer outras necessidades. O seu caráter estranho ressalta claramente do fato de se fugir do trabalho como da peste, logo que não exista nenhuma compulsão física ou de 
qualquer outro tipo. O trabalho externo, o trabalho em que o homem se aliena, é um trabalho de sacrifício de si mesmo, de mortificação. Finalmente, a exterioridade do trabalho para o trabalhador transparece no fato de que ele não é o seu trabalho, mas o de outro, no fato de que não the pertence, de que no trabalho ele não pertence a si mesmo, mas a outro. [...] Pertence a outro e é a perda de si mesmo.

Sobre a carga de trabalho, há de se destacar as divergências apresentadas nas entrevistas, pois de um lado, $50 \%$ dos docentes afirmaram considerar a carga de trabalho normal, do outro, $43 \%$ consideraram a mesma exaustiva, e $7 \%$, mais ou menos.

\section{Gráfico 2. Visão das docentes sobre a carga de trabalho}

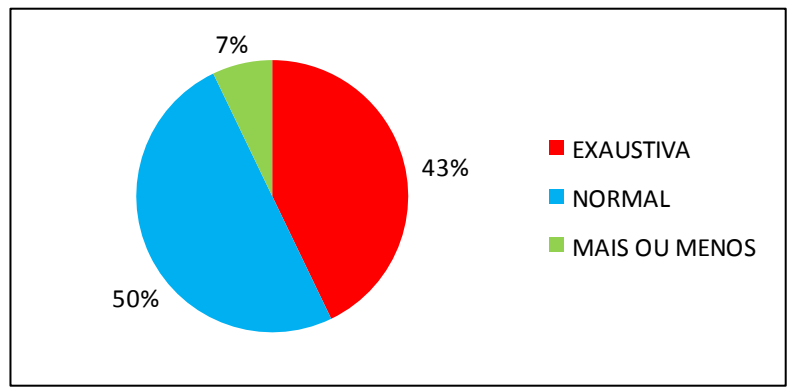

Esse quantitativo nos leva a refletir a postura dos docentes frente às respostas apresentadas ao questionário, pois, no decorrer da mesma questionaram a participação nas Atividades Complementares (AC) após o horário de serviço, bem como a sobrecarga da profissão, mas, no momento de avaliarem a carga de trabalho, afirmaram, em sua maioria, que a mesma é normal. Sobre esta questão, o Sujeito 5 nos diz o seguinte:

Olha, na escola (risos), assim de manhã e à tarde, somam quarenta horas, mas eu acho que é mais do que isso. Que eu chego em casa, quando você chega em casa, você tem que planejar, você tem que buscar mais. Eu acho que chega em torno de sessenta horas semanais ou mais. Isso que finais de semana tá sempre ali na busca, pesquisando e elaborando atividades, sempre em busca de coisas novas pra levar pra sala. (Sujeito 5)

Quanto à questão da alienação docente, os participantes se sentem lesados e cansados diante da profissão, entretanto, consideram normal fazer mais de 44 horas semanais, ultrapassando sua carga horária normal de trabalho. Neste ponto, as concepções de Batista e Codo (1999, p. 85) servem para compreender o porquê de as docentes vivenciarem a sobrecarga de trabalho e afirmarem que é normal. Isso se dá, de acordo com eles, devido ao fato de quanto maior "a defasagem entre o 'trabalho como deve ser' e a 'realidade do trabalho' nas escolas, maior será o investimento afetivo e cognitivo exigido ao professor, maior será o esforço realizado, e, por isso, maior será seu sofrimento no cotidiano do trabalho". 
Ao serem indagadas sobre a frequência com que se dedicam à saúde e ao lazer, o resultado demonstrou (gráfico 3) que 64\% relataram que às vezes se dedicam a isso, e 36\%, disseram que sempre. O resultado demonstrou que a saúde e o lazer sempre ficam em segundo plano. Esse dado se relaciona diretamente com o do gráfico 3 , pois, ao afirmarem que a rotina de trabalho é normal, não percebem que o tempo que deveria ser livre para o lazer e os cuidados com a saúde são destinados às atividades profissionais extras, o que nem elas mesmas compreendem como fator negativo.

\section{Gráfico 3. Dedicação docente à saúde e ao lazer}

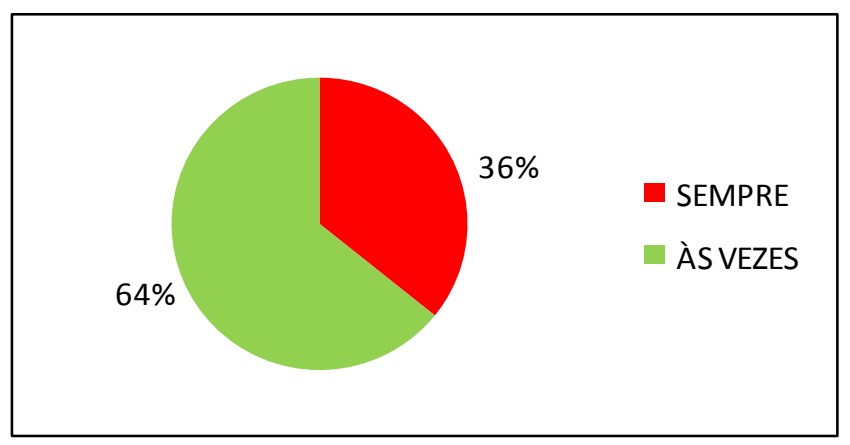

Em relação à frequiência com que se sentem estressadas no ambiente de trabalho, 93\% afirmaram que às vezes, $7 \%$ afirmaram que sentem estressadas sempre. O quantitativo apresentado no gráfico abaixo, embora possa parecer contrário ao que se observa, ele torna fidedigna a constatação de que a profissão docente é estressante. Sobre isso, Penna (2011, p. 148) destaca que exercer a docência '[...] não significa ocupar posição de prestígio social, uma vez que esse exercício está associado a angústias, instabilidades, ausência de autonomia, impotência, desrespeito, imposições, sobrecargas, medo, ou seja, relaciona-se a características negativas".

\section{Gráfico 4. Frequência com que o docente se sente estressado}

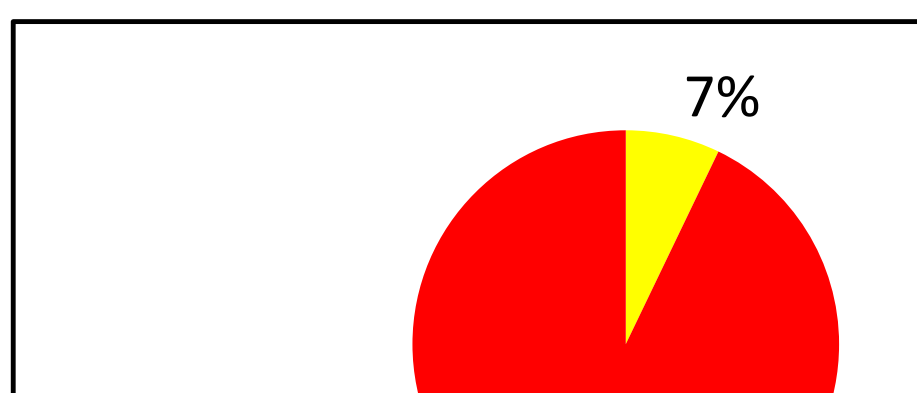

As concepções aqui destacadas coadunam com os estudos de Martins (2005, p. 222), em que esta autora afirma que“[...] o professor exerce sua docência e se encontra exposto a situações geradoras de desgastes físico e mental induzidos pelo stress ocupacional da atividade docente". As percepções dos autores demonstram que a profissão docente exige demais do indivíduo, 
especialmente frente às novas exigências educacionais, por isso, o crescimento observado do malestar docente.

Das 20 entrevistadas, apenas quatro afirmaram nunca terem tido problemas de saúde relacionados à profissão. Essa constatação nos leva a analisar que o sexo feminino é o mais atingido pelas doenças ocupacionais, isto, muito provavelmente, pelo fato de desempenharem jornadas duplas de trabalho e, não raro, triplas. As mulheres somam maior número de docentes não só em Medeiros Neto, mas, em todo o país, e além de serem professoras, são mães, esposas, domésticas etc., por isso, serem as mais afetadas no processo de adoecimento. A este respeito Bruschini (2000, p. 32) coloca que "[...] as mulheres seguem sendo as principais responsáveis pelas atividades domésticas [...], o que representa uma sobrecarga para aquelas que também realizam atividades econômicas [...]".

O gráfico 5 demonstra que, enquanto $29 \%$ afirmaram nunca terem apresentado problemas de saúde, $71 \%$ destacaram já terem tido alguma complicação com a saúde relacionada à sua profissão.

\section{Gráfico 5. Problemas de saúde relacionados ao trabalho docente}

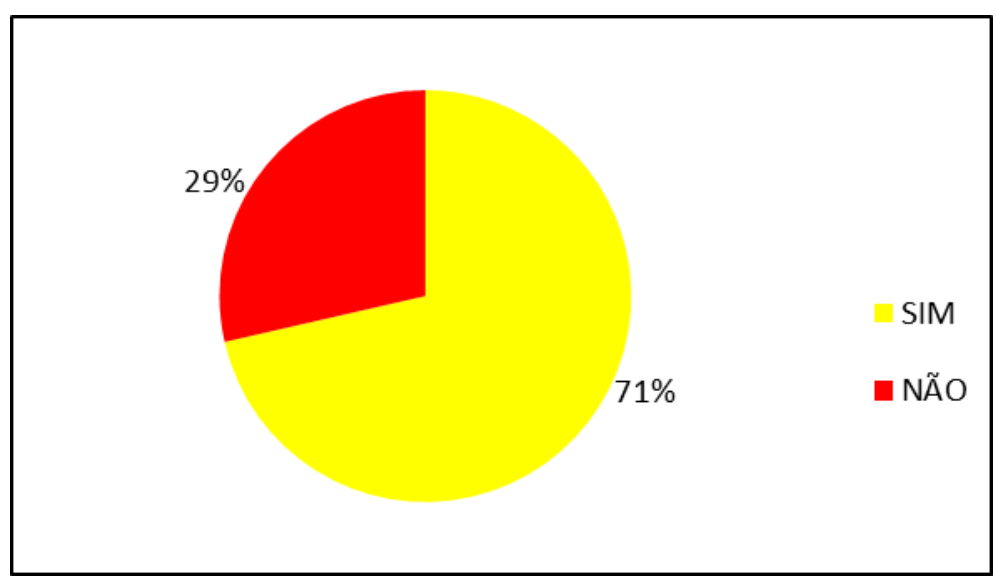

Os dados do gráfico 5 evidenciam, mais uma vez, o quanto o trabalho do docente é capcioso e, a depender da disponibilidade e da qualidade das condições laborais, tende a causar danos irreversíveis à saúde. Sobre esse aspecto, Abramides e Cabral (2003, p. 5) ressaltam que "a intensidade e o ritmo acelerado no trabalho e o número excessivo de horas na jornada são decisivos na precarização da saúde do trabalhador, podendo eliminá-lo, precocemente, do mercado”.

O gráfico 6 apresenta os sintomas mais recorrentes relatados pelas docentes. Cabe explicar que ele ocupa toda a página devido à quantidade de doenças apresentadas pelas professoras. Desta forma, a redução do mesmo se tornou inviável pelo fato de suprimir dados considerados importantes para a compreensão do todo. 


\section{Gráfico 6. Sintomas mais recorrentes no adoecimento docente}

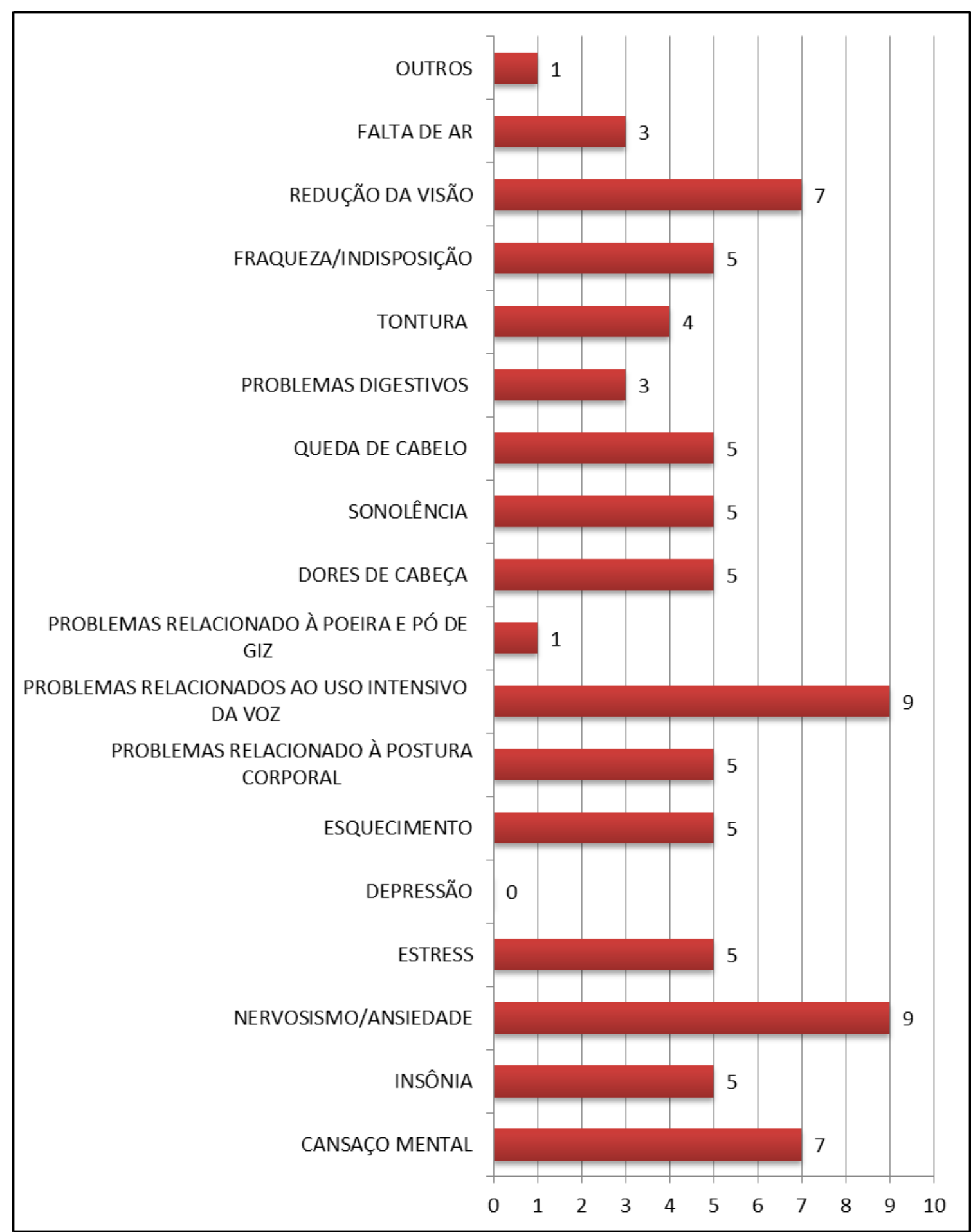


Pode se verificar neste gráfico que os sintomas relatados estão fortemente ligados com aquilo que diversos autores têm apresentado como sendo oriundos da precariedade das condições de trabalho docente. Os dados demonstram que a saúde dessas profissionais tem sido comprometida e elas não se dão conta ou se alienam diante da necessidade financeira e se calam, comprometendo ainda mais a saúde. Essa realidade de alienação atrelada ao amor à profissão é ressaltada por Codo (1999, p. 1), que assevera que:

[...] No Brasil, os professores trabalham em péssimas condições e com poucos recursos. Mas eles sabem da importância do seu trabalho e continuam fazendo de tudo para ensinar seus alunos. Em um quadro como este, onde um trabalho tão essencial é feito em condições tão ruins, o profissional acaba se desgastando emocionalmente.

O aparecimento desses sintomas e o possível adoecimento docente também são destacados por Jesus (1996, p. 25), que, fazendo menção ao mal-estar docente, alerta que isso se dá diante das inúmeras tentativas fracassadas de sucesso profissional, desencadeando, assim, as frustrações e o insucesso frente à aprendizagem, o que corrobora diretamente para o adoecimento do indivíduo. Destarte, o autor deixa claro que:

Se o professor não for bem sucedido e a tensão permanecer elevada durante muito tempo, pode manifestar sintomas de estresse que produzem a sua má adaptação à situação de exigência em que se encontra. Assim, o estresse faz parte do dia a dia, mas quando as exigências são intensas, excessivas, prolongadas ou imprevisíveis, ou quando o sujeito não possui as competências apropriadas para lidar com essas exigências, surgem os sintomas de mal-estar.

É pertinente evidenciar que o sintoma de síndrome do pânico foi relatado pelo Sujeito 11, quando ela contou que uma situação vivenciada dentro do ambiente escolar e a falta de apoio da gestão e da própria Secretaria Municipal de Educação acarretaram no seu processo de adoecimento. Nesse relato, a docente deixa clara não somente a falta de apoio da gestão municipal em si, mas de todo corpo administrativo e docente da unidade escolar na qual estava inserida. Essa realidade coaduna com a percepção de Codo (1999, p. 57), que discute sobre a importância do ambiente e das condições laborais para o sucesso do trabalho docente e como subterfúgio para evitar o processo de adoecimento psíquico do professor.

Agora, se o ambiente e as condições de trabalho são efetivamente hostis, a tendência é potencializar a possível dificuldade afetiva que o individuo venha a possuir, própria de sua estrutura de personalidade. Esta situação causa um grande desconforto para o sujeito e, em maior grau, pode ser desencadeadora de sofrimento psíquico. 
Este relato demonstra as variadas situações às quais os professores são submetidos no cotidiano de sua profissão. Nota-se que os problemas sociais interferem diretamente em seu trabalho, levando-os a desempenhar um papel que está aquém de suas funções habituais, fato que corrobora diretamente para seu processo de adoecimento, como mostra Oliveira (2004, p. 1132).

O professor, diante das variadas funções que a escola pública assume, tem de desempenhar papéis que estão para além de sua formação. Muitas vezes esses profissionais são obrigados a desempenhar as funções de agente público, assistente social, enfermeiro, psicólogo, entre outras. Tais exigências contribuem para um sentimento de desprofissionalização, de perda de identidade profissional, da constatação de que ensinar às vezes não é o mais importante.

Ao serem questionadas sobre como consideram o trabalho docente, os adjetivos "prazeroso", "criativo" e "desgastante" lideraram nos relatos. O que se percebe, desta forma, é que, apesar de tantos infortúnios, de tantas lutas diante de condições de trabalho que desmotivam, a função ainda é considerada prazerosa, especialmente pelas relações afetivas que são construídas no cotidiano da sala de aula.

\section{Gráfico 7. Como o docente considera seu trabalho}



Sobre os aspectos considerados fonte de tensão e cansaço no trabalho, a indisciplina dos alunos figurou como aspecto de maior impacto, seguido pelo fato de o educador não se sentir valorizado no âmbito de suas atividades docentes. A observação crítica cabível nesta discussão gira em torno, também, dos aspectos da alienação docente frente à percepção sobre aquilo que realmente contribui para seu processo de desistência, adoecimento etc. 


\section{Gráfico 8. Aspectos que são fonte de tensão no trabalho}

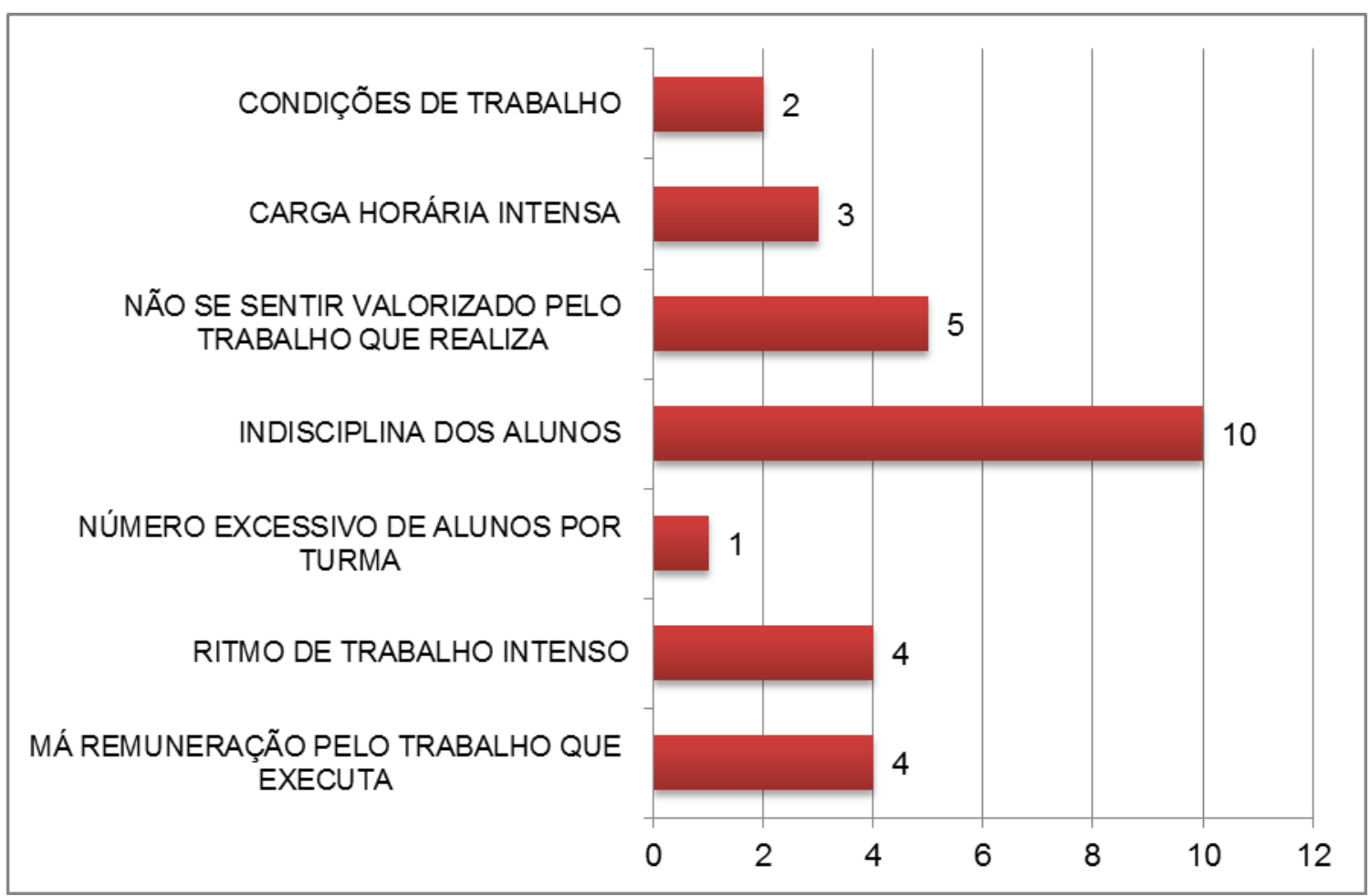

Os depoimentos da maioria das docentes deixam explícito que o entendimento a despeito de condições laborais ainda está atrelado à visão alienada, em que, mesmo frente à precariedade, os docentes não refletem criticamente sobre a própria situação de trabalho, e disseminam a falsa visão de professor feliz e realizado na profissão, quando, na verdade, suas expressões sobre diferentes aspectos o exercício da profissão revelam que são lesados cotidianamente. Mas, por não compreenderem e/ou refletirem, não se posicionam e não lutam em prol da melhoria da qualidade dessas condições. Essa situação demonstra que “[...] os docentes encontram-se submetidos a processos cuja tendência é a mesma que para a maioria dos trabalhadores assalariados: proletarização" (ENGUITA, 1989, p. 41).

\section{CONSIDERAÇÕES FINAIS}

Corroborando com estudos que discutem a relação direta entre carreira docente e adoecimento, além das nossas próprias observações, o resultado dessa pesquisa demonstra o quão desgastante pode ser a profissão de professor na realidade brasileira.

A escola, em muitos casos, é um ambiente de trabalho onde casos de violência, em conjunto com outros fatores, como desvalorização social e financeira, negligência de gestores, indisciplina etc., propiciam o surgimento de doenças ocupacionais, físicas e psicológicas, cujas repercussões abrangem a vida profissional e privada do professor. 
Este estudo, que demonstrou que apenas $43 \%$ das entrevistadas se dizem satisfeitas com a profissão, evidencia que há algo de errado, pois em qualquer empresa onde mais da metade dos profissionais estão descontentes, a produtividade não poderá ser eficiente. Em se tratando de ensino, esse dado é alarmante, compreendendo-se que o trabalho do professor tende a repercutir consideravelmente na vida dos alunos.

Os demais dados ratificam que o processo de desgaste da profissão docente se origina de fatores diversificados, assim como também deixa evidente que o fator gênero é um elemento importante, pois no período pesquisado não se verificou nenhum caso de afastamento de profissional do sexo masculino por problemas de doenças. Não é o caso de se pensar que a mulher seja o sexo frágil, mas sim que uma carga horária pesada (o trabalho em apenas em um turno não geraria renda suficiente para suas necessidades financeiras), aliada aos serviços domésticos que, salvo raras exceções, ficam sob sua responsabilidade, são os elementos que ocasionam o adoecimento da profissional docente.

Interessante perceber que, apesar de todos os problemas, da tensão do cotidiano escolar e das mazelas da educação, a profissão docente é prazerosa para a maioria das entrevistadas. Isso nos faz crer que o problema não está no professor que, afora todas as (compreensíveis) queixas e relatos de ansiedade e insatisfação, ainda ama sua profissão e quer fazer dar certo.

Então, considerando os resultados encontrados nessa pesquisa, podemos admitir que a profissão docente no município de Medeiros Neto, Bahia, encontra-se em situação igual aos demais municípios brasileiros. Ou seja, é uma profissão com riscos consideráveis à saúde dos trabalhadores. E as informações aqui apresentadas são importantes não somente para que se compreenda a situação, mas assim como também o é para que sejam pensadas formas de solucionar o problema.

Uma sociedade que não se importa com a saúde dos seus professores não está em situação de exigir desses profissionais um trabalho de qualidade, pois em um ambiente laboral onde existem fatores que propiciam o adoecimento físico e mental do trabalhador, não há como ser desenvolvido um trabalho de excelência. Isto é algo importante para se pensar quando as políticas públicas são elaboradas no sentido de pretender uma educação que seja transformadora. 


\section{REFERÊNCIAS}

ABRAMIDES, Maria Beatriz Costa; CABRAL, Maria do Socorro Reis. Regime de acumulação flexível e saúde do trabalhador. São Paulo em Perspectiva, v. 17, n. 1, p. 3-10, 2003.

BRUSCHINI, Cristina; ROCHA, Maria Isabel Baltarda. Gênero e trabalho no Brasil: novas conquistas ou persistência da discriminação. Trabalho e Gênero: mudanças, permanências e desafios. São Paulo, Editora, v. 34, p. 13-58, 2000.

CODO, Wanderley. Educação, carinho e trabalho: burnout, a síndrome da desistência do educador, que pode levar à falência da educação. [S.l.: s.n.], 1999.

DEJOURS, C. A loucura do trabalho. São Paulo: Cortez-Oboré, 1992.

ENGUITA, Mariano F. A face oculta da escola: educação e trabalho no capitalismo. Porto Alegre: Artes Médicas, 1989.

ESTEVE, J. M. O mal-estar docente: a sala de aula e a saúde dos professores. São Paulo: EdUSC, 1999.

FRANCELINO, S. M. R. L. As transformações do mundo do trabalho e a atividade docente. In: LEÃO, I.B. Educação e psicologia: reflexões a partir da teoria sócio-histórica. Campo Grande: Editora UFMS, 2003. p. 121-144.

HELLER, Agnes. O cotidiano e a história. São Paulo: Paz e Terra, 1985.

JESUS, Saúl Neves. A motivação para a profissão docente: Contributo para a clarificação de situações de mal-estar e para a fundamentação de estratégias de formação de professores. [S.1.: s.n.], 1996.

LIPP, M. N. O estresse do professor. Campinas: Papirus, 2002.

MASLACH, C.; LEITER, M.P. Trabalho: fonte de prazer ou desgaste. Campinas : Papirus, 1997.

MARTINS, Maria G. Teles. Sintomas de stress em professores das primeiras séries do Ensino Fundamental. Umestudo exploratório. Revista Lusófona de Educação, n. 6, p. 222-223, 2005.

MARX, Karl. Introdução à Crítica da Economia Política (Grundrisse). K. Marx Manuscritos Econômico-filosóficos e outros Textos Escolhidos. São Paulo: Abril Cultural, 1974. (Col. Os Pensadores, vol. XXXV).

OLIVEIRA, Dalila Andrade. A reestruturação do trabalho docente: precarização e flexibilização. Educação \& Sociedade, v. 25, n. 89, p. 1127-1144, 2004.

PENNA, Marieta Gouvêia de Oliveira. Exercício docente: posições sociais e condições de vida e trabalho e trabalho de profes sores. Araraquara: Junqueira \& Marin; São Paulo: Fapesp, 2011.

REIS, E.J.F.B.; ARAÚJO, T.M.; CARVALHO, F.M.; BARBALHO, L.; SILVA, M.O. Docência e exaustão emocional. Educacão \& Sociedade, 27 (94), 229-253, 2006. Disponível em: <http://www.scielo.br/pdf/es/v27n94/ a12v27n94.pdf>. Acesso em: 15 ago. 2013

ROCHA, K.B; SARRIEIRA, J.C. Saúde percebida em professores universitários: gênero, religião e condições de trabalho. Revista Semestral da Associação de Psicologia Escolar e Educacional (ABRAPEE), 10(2), 187-196, 2006.

TAVARES, E.D.; ALVES, F.A.; GARBIN, L S.; SILVESTRE, M.L.C.; PACHECO, R.D. Projeto de qualidade de vida: combate ao estresse do professor. [S.1.: s.n], 2007. Disponível em: <http://www.unicamp.br/fef/espec/ hotsite/gqve/TCC_GustavoElmaLuciaCi.madon.pdf>. Acesso em: 17 ago. 2013. 


\section{RESUMO}

Este artigo tem como objetivo apresentar uma análise da situação da saúde dos professores. O estudo toma como lócus empírico o município de Medeiros Neto, Bahia, com ênfase nos dados que se referem aos diversos fatores que, direta ou indiretamente, corroboram para o agravo da saúde desses profissionais. Como método de estudo, foi realizada entrevista para a coleta de dados junto a docentes da rede pública municipal de ensino. Os resultados apontam que em um período que corresponde de cinco anos, o número de professores que solicitaram afastamento de suas funções alegando motivos de saúde foi significativo. Assim, o estudo evidencia que há a necessidade de se implantar políticas públicas que ofereçam um ambiente laboral que possibilite ao professor exercer suas funções sem prejuízo de sua saúde física e mental.

Palavras-chave: Adoecimento docente. Saúde do professor. Trabalho docente.

\section{TEACHER ILLNESS: A BRIEF ANALYSIS OF HEALTH OF TEACHERS OF THE MUNICIPALITY OF MEDEIROS NETO/BA}

\section{ABSTRACT}

This article aims to present an analysis of the health situation of teachers. The study takes as empirical lócus the municipality of Medeiros Neto, Bahia, with emphasis on the data that refer to the various factors that, directly or indirectly, corroborate to the health of these professionals. As a method of study, an interview was conducted to collect data from teachers of the municipal public school system. The results show that over a five-year period, the number of teachers who requested leave of absence on health grounds was significant. Thus, the study shows that there is a need to implement public policies that offer a work environment that allows the teacher to perform his duties without impairing his physical and mental health.

Keywords: Teacher illness. Teacher Health. Teaching work.

\section{LA ENFERMEDAD DOCENTE: UNA BREVE ANÁLISIS DE LA SALUD DE PROFESORES DEL MUNICIPIO DE MEDEIROS NETO/BA}

\section{RESUMEN}

Este artículo tiene como objetivo presentar un análisis de la situación de la salud de los profesores. El estudio toma como lócus empírico el municipio de Medeiros Neto, Bahía, con énfasis en los datos que se refieren a los diversos factores que, directa o indirectamente, corroboran para el agravio de la salud de esos profesionales. Como método de estudio, se realizó una entrevista para la recolección de datos junto a docentes de la red pública municipal de enseñanza. Los resultados apuntan que en un período que corresponde a cinco años, el número de profesionales de la educación que solicitaron alejamiento de sus funciones alegando motivos de salud fue significativo. Así, el estudio evidencia que hay la necesidad de implantarse políticas públicas que ofrezcan un ambiente laboral que posibilite al profesor ejercer sus funciones sin perjuicio de su salud física y mental.

Palabras clave: Enfermedad docente. Salud de profesores. Trabajo docente.

Submetido em: 20 de janeiro de 2019 Aprovado em: 15 de maio de 2019 